\title{
DESENVOLVIMENTO DE BIOADSORVENTE A PARTIR DA VAGEM SECA DO FEIJÃO (Phaseolus vulgaris L.) MODIFICADA COM ÁCIDO TÂNICO PARA REMOÇÃO DE ÍONS METÁLICOS EM SOLUÇÃO AQUOSA: OTIMIZAÇÃO USANDO PLANEJAMENTO EXPERIMENTAL.
}

\author{
G. S. C. RAULINO ${ }^{1}$, C. B. VIDAL ${ }^{1}$, D. Q. MELO $^{2}$, L. S. da $\operatorname{SILVA}^{2}$ e R. F. do NASCIMENTO ${ }^{2}$ \\ ${ }^{1}$ Universidade Federal do Ceará, Departamento de Engenharia Sanitária e Ambiental \\ ${ }^{2}$ Universidade Federal do Ceará, Departamento de Química Analítica e Físico-Química \\ E-mail para contato: gisellescr@yahoo.com.br
}

\begin{abstract}
RESUMO - A influência de três variáveis foi avaliada no processo de modificação da casca do feijão para uso como adsorvente de íons metálicos em solução, utilizando planejamento fatorial. As variáveis $\mathrm{pH}\left(2,0 ; 5,5\right.$ e 9,0), temperatura $\left(30,50\right.$, e $\left.70{ }^{\circ} \mathrm{C}\right) \mathrm{e}$ concentração inicial $(0,02 ; 0,06$ e $0,1 \mathrm{M})$ foram estudadas em dois níveis e com ponto central. A capacidade de adsorção em solução multielementar $\left(\mathrm{Pb}^{2+}, \mathrm{Cd}^{2+}, \mathrm{Cu}^{2+}, \mathrm{Ni}^{2+} \mathrm{e}\right.$ $\mathrm{Zn}^{2+}$ ) dos materiais modificados foi utilizada como variável resposta. Foi possível observar que a variável $\mathrm{pH}$ foi significativa no processo de modificação para todos os íons metálicos sendo que o menor nível $(\mathrm{pH}=2,0)$ resultou em materiais com melhores capacidades de adsorção. A variável concentração inicial foi significativa na modificação para os íons cádmio e zinco. A variável temperatura não foi significativa para nenhum dos íons. A interação entre temperatura e concentração foi significativa na modificação para o íon cobre, indicando a formação de sítios específicos para este íon metálico.
\end{abstract}

\section{INTRODUÇÃO}

A atividade industrial tem incrementado o teor de íons metálicos tóxicos, tais como chumbo, cobre, cádmio, zinco e níquel em efluentes e consequentemente em águas naturais. A remoção efetiva desses compostos é um assunto de grande interesse devido a cada vez mais rigorosa legislação ambiental para o descarte dessas substâncias além dos efeitos negativos no corpo humano. Por outro lado, os chamados metais pesados são um recurso valioso para diferentes aplicações industriais. Portanto a recuperação e reciclagem são particularmente interessantes, especialmente do ponto de vista de proteção dos recursos (Gurgel e Gil, 2009a,b, Mao et al., 2013).

Técnicas como precipitação química, adsorção, eletrólise e osmose reversa tem sido empregadas na remoção desses poluentes. Contudo, o custo de operação e a qualidade do efluente final podem vir a ser um entrave no uso dessas técnicas. Assim, tecnologias alternativas, como a biossorção, têm sido desenvolvidas, onde materiais de baixo custo e disponíveis em grande 


\section{9 a 22 de outubro de 2014 \\ Florianópolis/SC}

quantidade são empregados no processo de adsorção (Song et al., 2013; Parka et al., 2010; Üçer et al., 2006, Mao et al., 2013).

Um material absorvente eficiente deve consistir de uma matriz estável e insolúvel, com grupos ativos que interagem com íons de metais pesados (Gurgel e Gil, 2009a). Como a biossorção se dá na superfície do material, a ativação ou aumento do número de sítios ativos é de particular interesse para o aumento de capacidade de adsorção de um biossorvente. Assim, processos de modificação na superfície de biossorventes têm sido empregados com a finalidade de aumentar a capacidade de adsorção dos mesmos (Mao et al., 2013; Parka et al., 2010; Song et al., 2013).

A metodologia de planejamento fatorial, ao contrário dos experimentos que variam um fator de cada vez, é uma excelente ferramenta para o estudo individual e dos efeitos de interação de todos os parâmetros simultaneamente. A razão para isto é que as variáveis podem influenciar umas as outras e o valor ideal para uma dessas variáveis pode depender dos valores de outra. Essa interação entre as variáveis é um fenômeno frequente (Carmona et al., 2005; Safa e Bhatti, 2011).

O objetivo do presente trabalho foi verificar a influência de três variáveis no processo de modificação com ácido tânico da vagem seca do feijão para uso como adsorvente de íons metálicos em solução aquosa, utilizando planejamento fatorial.

\section{MATERIAIS E MÉTODOS}

As vagens secas do feijão foram obtidas de pequenos produtores no interior do estado do Ceará - Brasil. As vagens foram trituradas em moinho de facas e em seguida foi realizado tratamento alcalino com $\mathrm{NaOH} 2,5 \mathrm{M}$, por 3 horas sob agitação. O material foi então lavado com água destilada até pH neutro e seco em estufa a $60^{\circ} \mathrm{C}$. Foi realizada a separação granulométrica e a faixa de 60 a 100 mesh foi utilizada neste trabalho.

Um planejamento fatorial completo (STATGRAPHICS Centurion, StatPoint technologies, Inc, VA 20186, USA) em dois níveis consistindo de 16+4 (pontos centrais) experimentos foi realizado a fim de determinar quais variáveis são significativas no processo de modificação das cascas de feijão com ácido tânico e melhorar a capacidade de adsorção. A Tabela 1 mostra os fatores e níveis estudados. Cada experimento foi conduzido em duas etapas da seguinte forma: na primeira etapa $40 \mathrm{ml}$ de uma solução aquosa de ácido tânico (Vetec, São Paulo, Brasil), na concentração, $\mathrm{pH}$ e temperatura de acordo com o planejamento, foi adicionada à $1,0 \mathrm{~g}$ de casca de feijão (60-100 mesh) sob agitação à 150 rpm por 2 horas. A solução sobrenadante foi descartada e o material adsorvente foi lavado com água destilada para remoção de excesso de ácido tânico. Ao material obtido foram adicionados $20 \mathrm{~mL}$ de glutaraldeído 0,5\% e deixado sob agitação a 170 rpm por 2 horas a fim de melhorar a resistência mecânica do material (Mao et al., 2013). Em seguida o material obtido foi lavado com água destilada e seco em estufa à $60^{\circ} \mathrm{C}$. 
Tabela 1 - Níveis dos fatores estudados no planejamento experimental.

\begin{tabular}{|c|c|c|c|c|}
\hline Variáveis & Símbolos & \multicolumn{3}{|c|}{ Níveis } \\
\hline & & -1 & 0 & +1 \\
\hline $\mathrm{pH}$ & $\mathrm{A}$ & 2,0 & 5,5 & 9,0 \\
\hline Temperatura $\left({ }^{\circ} \mathrm{C}\right)$ & $\mathrm{B}$ & 30 & 50 & 60 \\
\hline Concentração Inicial $(\mathrm{M})$ & $\mathrm{C}$ & 0,02 & 0,06 & 0,1 \\
\hline
\end{tabular}

Para cada material obtido foi realizado ensaio de adsorção em batelada onde $0,300 \mathrm{~g}$ de material foi adicionado a $25 \mathrm{~mL}$ de solução multielementar $3 \mathrm{mM}$ (milimols) de cada íon metálico $\left(\mathrm{Pb}^{2+}, \mathrm{Cu}^{2+}, \mathrm{Cd}^{2+}, \mathrm{Ni}^{2+}\right.$ e $\mathrm{Zn}^{2+}$; solução preparada a partir dos sais de nitrato de cada íon metálico em meio aquoso) em pH 5,5 por 3 horas à $300 \mathrm{rpm}$. As capacidades de adsorção (q) de cada material foram calculadas de acordo com a equação 01 e utilizadas como variável resposta no planejamento experimental de modificação da casca de feijão.

$$
q=\frac{\frac{(C i-C f)}{M M} * V}{m}
$$

Onde: q é a capacidade de adsorção em mmol/g, Ci e Cf são as concentrações iniciais e finais dos íons metálicos em solução, MM é a massa molar de cada íon metálico, v é o volume de solução e m a massa de material adsorvente.

\section{RESULTADOS E DISCUSSÕES}

O uso de planejamento experimental em um processo permite verificar todas as combinações possíveis de vários níveis dos fatores (ou variáveis) estudados. As variáveis $\mathrm{pH}$, temperatura e concentração de ácido tânico foram estudadas no processo de modificação da vagem seca do feijão e a capacidade de adsorção foi utilizada como resposta.

A Figura 1 apresenta os gráficos de pareto para cada metal onde são mostradas as variáveis significativas com $95 \%$ de confiança ( $\mathrm{p}$-valor). No gráfico todos as variáveis foram verificadas através da soma das capacidades de adsorção de todos os íons metálicos estudados. Pode-se observar que para todos os íons, inclusive a soma, a variável $\mathrm{pH}$ significativa. $\mathrm{O}$ aumento no $\mathrm{pH}$ de 2,0 para 9,0, implicou na redução na capacidade de adsorção, indicado que o processo de modificação ocorre em maior grau em pH ácido. Mao et al. (2013) estudando a remoção de cádmio por biomassa de bactéria modificada com ácido poliacrílico indicaram que a ligação química se dá entre os grupos hidroxila da biomassa e os grupos carboxílicos do ácido poliacrílico e essa reação é catalisada em $\mathrm{pH}$ ácido.

Na Figura 1 ainda pode ser visto que a interação entre as variáveis temperatura e concentração inicial de ácido tânico foi significativa para o íon cobre. É possível que o aumento da temperatura e da concentração de ácido tânico tenha promovido a formação de sítios específicos para os íons cobre ou seus complexos formados em solução $\left(\mathrm{Cu}_{2}(\mathrm{OH})_{2}{ }^{2+}, \mathrm{CuOH}^{+}, \mathrm{Cu}_{2} \mathrm{OH}^{3+}, \mathrm{Cu}_{3}(\mathrm{OH})_{4}{ }^{2+}\right)$. A variável 
concentração inicial foi significativa para os íons cádmio e zinco, indicando que o aumento da concentração inicial resultou em mais sítios disponíveis para remoção dos íons em solução. Üçer et al. (2005), estudando a imobilização de ácido tânico em carvão ativado para remoção de ferro (III), observou que tanto o aumento da temperatura quanto da concentração inicial de ácido tânico em solução resultou em um aumento da quantidade de ácido tânico imbolilizado, corroborando os dados encontrados neste trabalho.
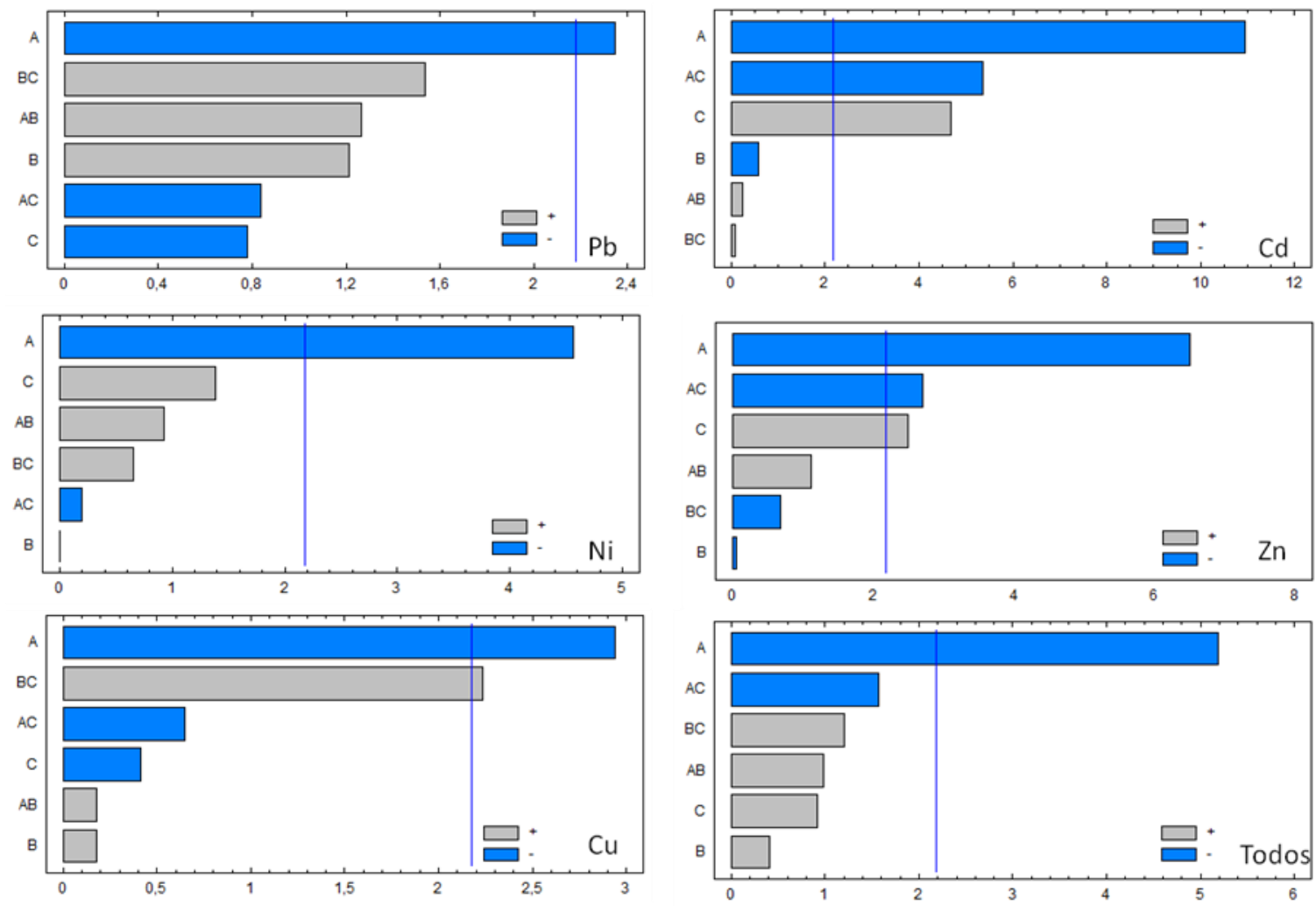

Figura 1 - Gráficos de Pareto dos efeitos padronizados dos íons metálicos estudados e variáveis significantes com $95 \%$ de confiança.

Na Figura 2 são apresentados os percentuais de remoção dos íons metálicos estudados pela vagem seca do feijão bruto, tratado com hidróxido $2,5 \mathrm{M}$ e modificada com ácido tânico nas condições: $\mathrm{pH}=2,0$, temperatura $=30^{\circ} \mathrm{C}$ e concentração inicial de ácido tânico $=0,1 \mathrm{M}$. É possível notar que houve aumento no percentual de remoção para todos os íons entre material bruto e tratado. Pode-se observar também que entre o tratamento alcalino e a modificação com ácido tânico ouve ainda aumento no percentual de remoção, indicando que a reação entre a superfície do material e o ácido tânico em solução ocorreu. Quase todos os íons cobre e íons chumbo são removidos enquanto que os percentuais de remoção para os outros três íons variam 
entre 40 e $50 \%$ no material tratado com ácido tânico. Isso é um indicativo de que o aumento na concentração inicial resultou em mais ácido tânico aderido à superfície do biossorvente, ou seja, mais sítios ativos ficaram disponíveis para remoção desses íons. As capacidades de adsorção para as mesmas condições acima citadas foram de $0,165 \mathrm{mmol} / \mathrm{g}$ para o íon cobre; $0,185 \mathrm{mmol} / \mathrm{g}$ para o íon chumbo; $0,085 \mathrm{mmol} / \mathrm{g}$ para o íon cádmio; $0,076 \mathrm{mmol} / \mathrm{g}$ para o íon níquel e $0,105 \mathrm{mmol} / \mathrm{g}$ para o íon zinco.

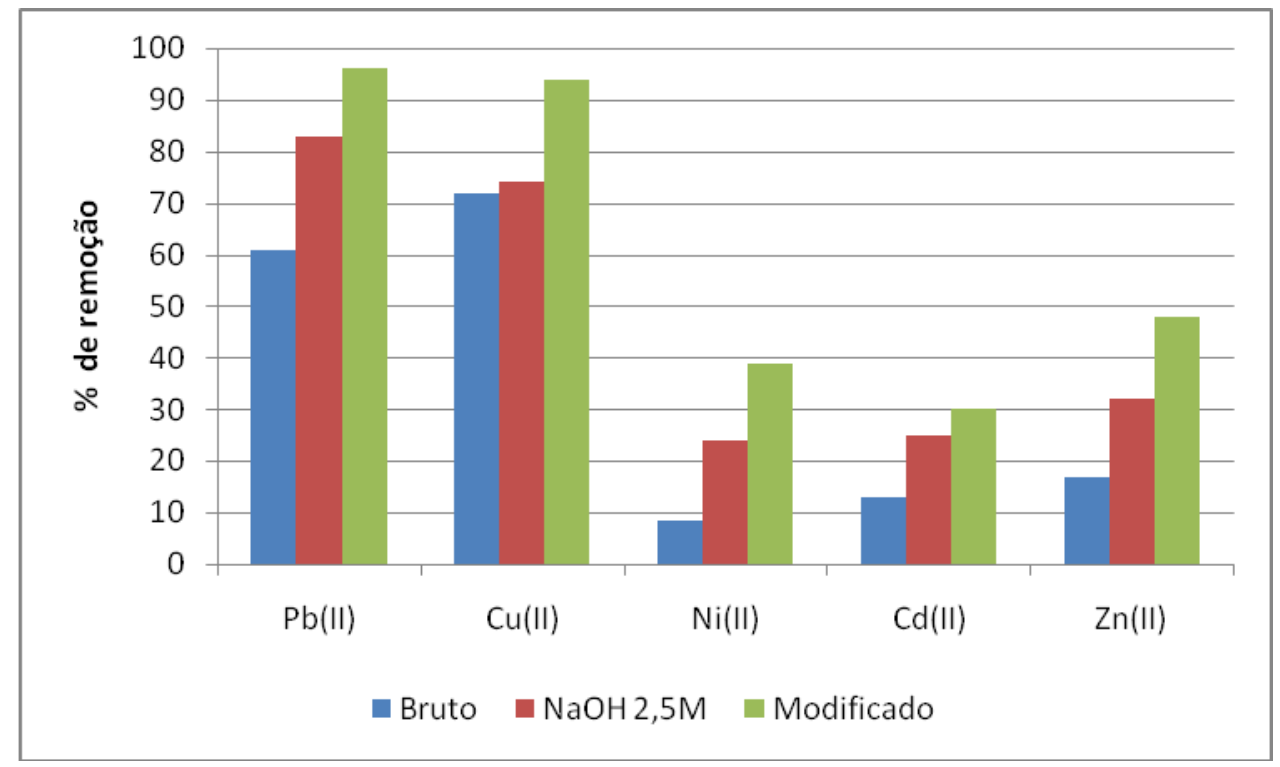

Figura 2 - Percentuais de remoção dos íons metálicos do material bruto, tratado com hidróxido e modificado com ácido tânico (Condições do material modificado com ácido tânico: $\mathrm{pH}=2,0$, temperatura $=30^{\circ} \mathrm{C}$ e concentração inicial de ácido tânico $\left.=0,1 \mathrm{M}\right)$.

Os resultados obtidos no presente trabalho foram comparados com alguns trabalhos da literatura e os dados são apresentados na tabela 2. É possível notar que a capacidade de adsorção no presente trabalho não foi tão boa em relação aos demais trabalhos. Contudo isso pode ser devido às condições ainda não otimizadas em relação ao estudo de adsorção. Os trabalhos encontrados na literatura realizaram estudos de isoterma indicando as capacidades máximas de adsorção encontradas para os respectivos materiais. Os estudos de isoterma serão realizados posteriormente e sob condições experimentais otimizadas. O presente trabalho visou apenas verificar as influências de três variáveis no processo de modificação. 
Tabela 2: Comparação entre as capacidades de adsorção de vários biossorventes modificados.

\begin{tabular}{|c|c|c|c|c|c|c|c|c|}
\hline \multirow{2}{*}{ Biossorvente } & \multirow{2}{*}{$\begin{array}{l}\text { Concentração } \\
\text { Inicial }(\mathrm{mM})\end{array}$} & \multirow[t]{2}{*}{$\mathrm{pH}$} & \multicolumn{5}{|c|}{$\mathrm{Q}(\mathrm{mmol} / \mathrm{g})$} & \multirow{2}{*}{ Referência } \\
\hline & & & $\mathrm{Cu}^{2+}$ & $\mathrm{Pb}^{2+}$ & $\mathrm{Cd}^{2+}$ & $\mathrm{Ni}^{2+}$ & $\mathrm{Zn}^{2+}$ & \\
\hline $\begin{array}{l}\text { Vagem seca do } \\
\text { feijão }\end{array}$ & 3 & 5,5 & 0,165 & 0,185 & 0,085 & 0,076 & 0,105 & $\begin{array}{l}\text { Presente } \\
\text { trabalho }\end{array}$ \\
\hline $\begin{array}{c}\text { Bagaço de cana } \\
\text { mercerizado e } \\
\text { funcionalizado com } \\
\text { trietilenotetramina }\end{array}$ & $1,5-3$ & $\sim 5,5$ & 1,66 & 1,07 & 1,4 & - & - & $\begin{array}{c}\text { Gurgel e } \\
\text { Gil, 2009a }\end{array}$ \\
\hline $\begin{array}{l}\text { Carvão ativado } \\
\text { imobilizado com } \\
\text { ácido tânico }\end{array}$ & $0,01-0,1$ & $\sim 5,0$ & 0,03 & - & 0,01 & - & 0,02 & $\begin{array}{l}\text { Üçer, } \\
\text { Uyanik, e } \\
\text { Aygün, } \\
2006\end{array}$ \\
\hline $\begin{array}{l}\text { Biomassa Bacteriana } \\
\text { modificada com } \\
\text { ácido poliacrílico }\end{array}$ & 5,3 & 6,0 & - & - & 1,23 & - & - & $\begin{array}{c}\text { Mao et al., } \\
2013\end{array}$ \\
\hline $\begin{array}{c}\text { Celulose } \\
\text { mercerizada } \\
\text { modificada com } \\
\text { trietilenotetramina }\end{array}$ & $1,0-1,5$ & $\sim 5,5$ & 1,1 & 0,92 & 0,77 & - & - & $\begin{array}{c}\text { Gurgel e } \\
\text { Gil, 2009b }\end{array}$ \\
\hline
\end{tabular}

\section{CONCLUSÕES}

Foi possível verificar a influência de três variáveis no processo de modificação com ácido tânico da vagem seca do feijão para uso como adsorvente de íons metálicos em solução aquosa, utilizando planejamento fatorial. A variável $\mathrm{pH}$ foi a que influenciou significativamente o processo de modificação com ácido tânico da vagem do feijão seca, ou seja, a redução do pH no processo de resultou em materiais com melhores capacidades de adsorção. O aumento da concentração inicial de ácido tânico resultou num efeito positivo para os íons cádmio e zinco. A interação entre temperatura e concentração inicial foi significativa apenas para o cobre.

\section{REFERÊNCIAS}

CARMONA, M.E.R.; DA SILVA, M.A.P.; LEITE, S.G.F. Biosorption of chromium using factorial experimental design, Process Biochem. v.40, p. 779-788, 2005.

GURGEL, L. V. A.; GIL, L. F. Adsorption of $\mathrm{Cu}(\mathrm{II}), \mathrm{Cd}(\mathrm{II})$ and $\mathrm{Pb}$ (II) from aqueous single metal solutions by succinylated twice-mercerized sugarcane bagasse functionalized with triethylenetetramine. Water Res. v. 43, p. 4479-4488, $2009 a$. 
GURGEL, L. V. A.; GIL, L. F. Adsorption of $\mathrm{Cu}(\mathrm{II}), \mathrm{Cd}(\mathrm{II})$, and $\mathrm{Pb}$ (II) from aqueous single metal solutions by succinylated mercerized cellulose modified with triethylenetetramine.Carbohydrate Polym. v.77, p. 142-149, 2009 b.

MAO,J.; WON, S. W.; YUN, Y. S. Development of Poly(acrylic acid)-Modified Bacterial Biomass As a High-Performance Biosorbent for Removal of Cd(II) from Aqueous Solution. Ind. Eng. Chem. Res. v. 52, p. 6446-6452, 2013.

PARKA, J.; WONA, S. W.; MAOB, J.; KWAKB, I. S., YUN, Y. S. Recovery of Pd(II) from hydrochloric solution using polyallylamine hydrochloride-modified Escherichia coli biomass. $J$. Hazard. Mater. v.181, p. 794-800, 2010.

SAFA, Y.; BHATTI, H. N. Adsorptive removal of direct textile dyes by low cost agricultural waste: Application of factorial design analysis. Chem. Eng. J. v. 167, p. 35-41, 2011.

SONG, M. H.; WONB, S. W.; YUN, Y. S. Decarboxylated polyethylenimine-modified bacterial biosorbent for $\mathrm{Ru}$ biosorption from Ru-bearing acetic acid wastewater Chem. Eng. J., v. 230,p. 303-307, 2013.

ÜÇER, A.; UYANIK, A.; ÇAY, S.; ÖZKAN, Y. Immobilisation of tannic acid onto activated carbon to improve Fe(III) adsorption. Sep. Purif. Tech. v. 44, p. 11-17, 2005.

ÜÇER, A.; UYANIK, A.; AYGÜN, Ş. F. Adsorption of Cu(II), Cd(II), Zn(II), Mn(II) and Fe(III) ions by tannic acid immobilised activated carbon. Sep. Purif. Tech. v. 47, p. 113-118, 2006. 